\title{
On Novels as Arguments
}

\author{
Gilbert Plumer
}

Associate Director for Assessment

Projects and Research (retired)

Law School Admission Council

1812 Laurel Oak Dr. N.

Rockledge, FL 32955 USA

plumerge@gmail.com

\begin{abstract}
If novels can be arguments, that fact should shape logic or argumentation studies as well as literary studies. Two senses the term 'narrative argument' might have are (a) a story that offers an argument, or (b) a distinctive argument form. I consider whether there is a principled way of extracting a novel's argument in sense (a). Regarding the possibility of (b), Hunt's view is evaluated that many fables and much fabulist literature inherently, and as wholes, have an analogical argument structure. I argue that a better account is that some novels inherently exhibit a transcendental argument structure.
\end{abstract}

Resumé: Si des romans peuvent être des arguments, ce fait devrait influencer des etudes dans la logique ou l'argumentation ainsi que dans la littérature. Deux sens que l'expression «argument narratif» pourrait avoir sont (a) une histoire qui offre un argument,ou (b) une forme distincte d'argument. J'examine s'il y a un moyen juste d'extraire un argument d'un roman dans le sens (a). En ce qui concerne la possibilité (b), j'évalue le point de vue de Hunt que plusieurs fables et beaucoup de littérature fabuliste ont intrinsèquement et dans l'ensemble une structure d'un argument par analogie. Je soutiens qu'une meilleure description est que certains romans présentent intrinsèquement une structure d'argument transcendental.

Keywords: analogical argument, ethical criticism, Walter Fisher, narrative argument, novels, Martha Nussbaum, transcendental argument, truth in fiction

\section{Introduction}

I tell you he [Abraham Lincoln] got more arguments out of stories than he did out of law books, and the queer part was you couldn't answer 'em- they just made you see it and you couldn't get around it. (Tarbell, p. 9)

The common view (at least among nonrhetoricians) is that no novel is an argument, though it might be reconstructed as one. This is curious, for we almost always feel the need to recon- 
struct arguments even when they are uncontroversially given as arguments, as in a philosophical text. What are we doing then? We are making the points as explicit, orderly, and (often) brief as possible, which is what we do in reconstructing a novel's argument. Moreover, the reverse is also true. Given a text that is uncontroversially an explicit, orderly, and brief argument, in order to enhance plausibility, our first instinct is to flesh it out with illustrations and relationships to everyday life. In other words, we expand the premises. If this process is fictive (as with 'thought experiments') and orderly, it is story-telling. So there is intuitive reason to think that a novel can be an argument, whether the argument is taken as writ large or writ small-full or condensed.

Is this intuition true? This matters because if novels can be arguments, then perhaps the fundamental value and defense of the novel is that reading novels may be critical to one's learning how to think, a fact that would have implications for the importance of literary studies as well as for their pedagogical approaches. If novels can be arguments, then that fact should also shape logic or argumentation studies. Ayers draws a useful distinction between two senses that the term 'narrative argument' might have: (a) a story that offers an argument, or (b) a special argument form or structure (pp. 2, 11-12, 36-37). After drawing further preliminary distinctions in section 2 below, in section 3 we will consider whether there is a principled way of determining or extracting a novel's argument in sense (a). The views of such authors as Nussbaum and Fisher will be evaluated. The possibility indicated by (b) will be first taken up in section 4. This possibility may be of unique interest for argumentation studies insofar as it seems that for all other kinds of cases, the source of an argument need not imply anything about the argument's structure. It is only rarely claimed that fictional narratives themselves, as wholes, can exhibit a distinctive argument structure (form, scheme). We will consider Hunt's view that many fables and much fabulist literature inherently have the structure of a kind of analogical argument. I will then in section 5 propose what seems to be a better account, which takes some novels to inherently exhibit the structure of a kind of transcendental argument.

\section{Further preliminary distinctions}

I mean 'argument' in the logical sense of a timeless, Platonic object, as opposed to a rhetorical or historical creation that is dependent in an essential way upon the circumstances or inten- 
tions of the audience or author. The logical or philosophical notion of arguments taken to be abstract sequences of propositions may be the ordinary notion, at least when we are thinking clearly (of course, not every scholar subscribes to this notion of argument; for more defense of it, see, e.g., Smith \& Moldovan). The contrasting relativistic notion of an argument seems to be a product of confusing the means by which we access arguments with arguments themselves. This distinction is particularly pertinent here because of the "messiness" of novels, which might be thought to mean that the argument would have to be a rhetorical or historical creation. As Doody writes (pp. 154-155, 158):

Philosophy [is]...proudly divorced from the mess of living...The Novel, however, lives in the kitchen, the bedroom, the street and the marketplace...[It] is full of characters chattering, giving themselves away as we say, making an exhibition of themselves...It is never transcendent. The novel never flies. Its strength is in what it is accused of - that it is a bundle of lies. Morally transgressive from that simple fact, it cannot commit the bad faith of offering pure solutions or a timeless world.

My point is that however messy the vehicle by which a novel's argument may be expressed, and however relative to contingencies its identification may be, the argument itself would have to be as timeless or abstract as any.

This is not to say that the subject matter or topic of a novel's argument could be as timeless or abstract as any. Given the messiness of novels - the fact that they are one and all primarily about (human) psychology, action, and society - the argument of a novel could not be on a wholly unrelated topic. For example, the argument of a novel could not be a mathematical proof or even make the physical case for the existence of a postulated entity (although a science fiction novel might push the envelope about what is physically possible). In terms of subject matter, the primary elements and connective of a novel, like any narrative, inherently are events and causality, not propositions and logical consequence.

This indicates a fact about technique that should be disentangled: the argument of a novel, if indeed a novel can be an argument, would have to be indirectly expressed. A novel cannot be an overt argument any more than there could be logical relations between events. In contrast, philosophy, for example, generally wears its cognitive content on its sleeve. I will return to this point in section 4 . 
Why is my focus on novels rather than other forms of fictional narration such as short stories, plays, and films? The novel is generally regarded as the pinnacle of fictional narrative art. Although for the most part I will do so, I do not see anything essential in focusing on novels in the attempt to discern argument in virtue of fictional narration. However, it does seem essential or necessary that the narration be fictional - that it not be, for example, history. This is not because history, biography, etc. need be any less vivid than fictional narration (the chain of thought is not: "vivid, therefore persuasive, therefore an argument"). Rather, it is because, by definition, the point of nonfictional narration involves veracity-sticking to the facts, telling what happened - so there is no theoretical room for the creativity that is needed to construct an argument by inventing what happens. (That is to say, more precisely, there is no theoretical room for the creativity that is needed to construct the means of accessing or identifying an argument by inventing what happens.) Perhaps Aristotle meant something like this when he famously said in the Poetics that "poetry is a more serious and philosophical business than history; for poetry speaks more of universals, history of particulars" (1451b 6-8).

\section{Extracting a novel's argument}

An approach to literary studies that might appear to offer help in determining a novel's argument is called "ethical criticism" or the "edifying tradition." According to Posner (esp. p. 458), this approach holds that the quality of a literary work is largely a function of the moral correctness of the views it may be taken to express, and that immersion in literature can make us ethically better people. Insofar as Plato found little or no value in what he regarded as immoral literature, he originated a version of ethical criticism. A prominent recent proponent is Nussbaum (e.g., 1995; cf. Booth 1988 and 1998). The opposing approach to ethical criticism is "aestheticism," which has its roots at least as far back as Kant, with his view that (proper) judgments of beauty are disinterested, and are made apart from any consideration of the usefulness of the object. Posner is an example of a recent aesthetic.

How might immersion in literature make us ethically better people, and how might a novel be taken to express a (moral) viewpoint? Our concern is what role or roles argument is supposed to have here. Nussbaum's answer revolves around the point that immersion in literature helps to develop the sympathetic imagination, which works toward a good end or has good 
social effects, at least in the case of some novels. She says, for example (1995, pp. 5, 34):

...literary works typically invite readers to put themselves in the place of people of many different kinds and to take on their experiences...The reader's emotions and imagination are highly active as a result...reading a novel like this one [Charles Dickens' Hard Times] makes us acknowledge the equal humanity of members of social classes other than our own, makes us acknowledge workers as deliberating subjects with complex loves and aspirations and a rich inner world.

For Nussbaum, novels stimulate the sympathetic imagination; that is what they contribute that is special in making us recognize such things as the equal humanity of others and making us have respect for them as persons. It is not supposed to be argument (though we will see a qualification to this in section 5 below). Nussbaum says, for instance, "an ethics of impartial respect for human dignity will fail to engage real human beings unless they are made capable of entering imaginatively into the lives of distant others" (1995, p. xvi). Nussbaum writes as if stimulation of the sympathetic imagination is needed simply as a complement to more formal ethical approaches. Other ethical critics, however, are radically anti-argument. For example, Crocker discusses the "moral transformation" of Huck in coming to see, in a kind of Gestalt shift, the escaped slave Jim as human in Mark Twain's The Adventures of Huckleberry Finn. Crocker says about this transformation that some might hold that "to be legitimate, it must be possible to reconstruct the transformation according to rational considerations. The ability to 'get behind' the transformation in some justificatory way is what I am denying here (as is Wittgenstein)" (p. 58). The same applies for any reader who experiences a "moral transformation" like Huck's, something that was presumably more common in Twain's day.

So what Nussbaum is postulating here with the stimulated sympathetic imagination, and Crocker with coming to see the world in a certain way (e.g., p. 72), is a nonargumentative vehicle, yet one that is nonetheless a vehicle of persuasion or "moral conversion" (Crocker, p. 70). I think that if this sort of thing is all there is to the persuasive force of novels, then that force is cheapened compared to what it would be if it also included an argumentative component. Noncognitive avenues of persuasion tend to be fickle (lacking the reliability of 'the caustic of reason') and even dangerous. It seems to be a psychological fact 
that "the effort to picture the inner lives of others most exerts itself when the others are strange, not when they are pitiable" and not when their "poverty is drab, depressing, and common" (Pappas, p. 286). Even defenses of the value of noncognitive vehicles of persuasion such as iconic photographs, against the view that they are "threats to practical reasoning," allow (for example) that they may "create a strong but open-ended emotional response" (Hariman \& Lucaites, pp. 14, 21). Certainly, it seems pretty obvious that reading novels produces much or most of its effect on us through affective means such as vivid description and situation or character identification. What I would like to urge, however, is that the effect that reading novels has on us is in fact much greater than it would be if Nussbaum and Crocker were right. Correspondingly for the novelist, if Nussbaum and Crocker were right, there would be far less point in writing a novel.

Recall that a tenet of ethical criticism involves that a novel may in fact be taken to express an ethical viewpoint. Now our question is, exactly how do ethical critics discern the ethical viewpoint of a novel? We have seen that it is not supposed to be by discerning the novel's argument. As far as I can tell, at least Nussbaum and Crocker do not propose and defend any method of discerning the ethical viewpoint of a novel. Rather, sufficiently didactic or polemical novels are chosen, and the ethical viewpoint expressed is simply identified, more or less, with what the polemic is generally regarded as for or against.

In contrast, Fisher and Filloy do suggest a method. Indeed, they believe that "some dramatic and literary works do, in fact, argue" (p. 343), and they indicate a procedure for determining the argument: First the reader or "auditor is induced to a felt belief, a sense of the message advanced by the work." This sense of the message is "aesthetic" in that it is an "immediate, emotional, intuitive response to the work," based on simply experiencing the work and its characters involved in various situations and conflicts whereby "different value orientations" are exhibited. Then "the auditor returns to the work and recounts the elements" that led to the initial sense of the message. This becomes "the reasoned account of the message" through a process of discerning "patterns" in the work of consistent descriptions as well as character actions that "dominate and survive" in the various situations and conflicts. Such patterns support conclusions, and this puts the work "within the realm of argument" (p. 347).

Since they hold that only "some dramatic and literary works...argue," presumably Fisher and Filloy would say that a work argues if (and only if) this process can be applied naturally_without being forced - to the work. In their paper, they ap- 
ply it in detail to Arthur Miller's play Death of a Salesman and F. Scott Fitzgerald's novel The Great Gatsby. As summarized above, their account seems reasonable as an outline of how one would extract a literary work's argument. However, they do express additional points that make the account uncomfortably relativistic. One point is that the argument so-derived is an "aesthetic proof" since it has its "origin in an aesthetic response to the work's elements" on the part of the auditor or reader (p. 347; cf. p. 346). The argument seems to depend in an essential way on the response of the audience. This is confirmed where Fisher and Filloy indicate that in arriving at the "reasoned account of the message" one is supposed to test "the validity of characters" against one's own sense of reality or plausibility and make adjustments to the account accordingly, so that "different auditors may arrive at different interpretations" (pp. 347-348).

Fisher and Filloy also make some interesting but vague remarks indicating that they think that "aesthetic proofs" are not narrative arguments simply in the sense of (a) a story that offers an argument, but also constitute (b) a distinctive argument form or structure. They say (p. 247) that "aesthetic proofs"

\begin{abstract}
are outside the traditional realm of argumentative proof in that they are neither general principles that form the basis of deduction nor are they real examples that can be the basis of induction. Such proofs offer a special representation of reality somewhere between analogy and example: what they represent is not exactly our own world but it must bear a relationship to it more essential than that of analogy.
\end{abstract}

This is, I think, all they say in attempting to spell out a distinctive structure for fictional narrative arguments. So let us turn to this topic directly, beginning with a view that appears to deny part of what Fisher and Filloy claim.

\title{
4. A proposed structure of narrative arguments: Analogical
}

Hunt proposes that many fables and much fabulist literature inherently have the structure of a kind of analogical argument (esp. p. 380). What is often cited as the form of an argument from analogy $-\mathrm{X}$ and $\mathrm{Y}$ have certain properties in common, $\mathrm{X}$ has some further property, so $\mathrm{Y}$ has the further property as well-Hunt sees as wanting, for the usual reason that having the first properties in common might not have anything to do with whether they have the further property in common (p. 372). In- 
stead, he proposes that at least literary arguments from analogy have a "first case/principle/second case' structure, where the principle is in Peircean fashion "abduced" from the first casethe principle "is supported to the extent that it is a good explanation of the first case." The second case, however, is deduced from the principle (p. 373). Hunt's view is evidently supposed to differ from standard reductionist analyses of analogical argument such as Beardsley's, both in that abducing the principle is not the same as uncovering a "hidden generalization," and in that it denies that "when we make that generalization explicit, we can throw away the rest of the analogy" (Beardsley, p. 113). Hunt says "if the principle does support the second case in the requisite way, then these properties [that the analogy invokes] will also appear in the first case" (p. 374). For illustration, consider this short fable, "The Boy and the Filberts" (http://www.aesopfables.com/cgi/aesop1.cgi?1\&TheBoyandtheF ilberts):

A BOY put his hand into a pitcher full of filberts. He grasped as many as he could possibly hold, but when he tried to pull out his hand, he was prevented from doing so by the neck of the pitcher. Unwilling to lose his filberts, and yet unable to withdraw his hand, he burst into tears and bitterly lamented his disappointment. A bystander said to him, "Be satisfied with half the quantity, and you will readily draw out your hand." Do not attempt too much at once.

The first case is the boy's experience with the filberts that is described. The principle is stated prescriptively or as a moral here, but stated as an explanation, the problem is that the boy attempted too much. (Of course there are other possible explanations or variations of this explanation, notably, that the boy was greedy.) The deduction of the second case is where readers apply the principle "to guide their own moral conduct or persuade others" (Hunt, p. 379).

Hunt indicates that, typically, the written analogical argument, as in the Filberts case, is incomplete or enthymematic. It must be completed by the reader. Often not only the second case, but the principle as well, must be filled in by the reader for fables and fabulist literature. One thing Hunt says about this is that "readers have only gotten the point of the narrative when they have, in one way or another, completed the analogy" ( $p$. 380). An example of adult fabulist literature Hunt mentions (pp. 380-381) is Arthur Miller's 1953 play, The Crucible, about witch-hunting in old Salem, Massachusetts, with parallels to anti-Communist 'witch-hunts' to be supplied by contemporary au- 
diences. Does all fictional literature have a point? Judging by the phenomenology of experiencing some of it, no. For example, consider the recent U.S. television series Lost and perhaps James Joyce's Ulysses. But it does seem, essentially by definition, that fabulist literature has to have a point. Such literature is in that way argumentative even if Hunt's particular analysis is wrong. That some novels do not have a point suggests that not all novels are arguments, a qualification to which we shall return. A related idea, which Hunt seems to suggest (pp. 379-381; cf. Lamarque, p. 122), is that how literary a fable is, is in part determined by the extent to which its (analogical) argumentative structure is incomplete. The more overtly moralistic the piece is, or the more the author supplies details of the second case, the less literary the piece tends to appear.

This aligns with a claim I made earlier - that if indeed a novel can be an argument, the argument would have to be indirectly expressed. For otherwise, the work's literary status (in the sense applied to fiction), and hence its status as a novel, would be called into question. The piece might be hard to distinguish from a work of philosophy built around an elaborate 'thought experiment', for example. In any case, it may seem that, by extension, Hunt's view about fables furnishes a possible way of understanding some entire novels as exhibiting a distinctive argument structure: they are a kind of enthymematic argument from analogy. Such notions have been advocated by others; for example, Rodden in a vaguer way discusses how the "enthymematic" analogy between our world and the world of George Orwell's 1984 may "move" or persuade us (e.g., pp. 165-167; cf., e.g., Walton).

Nevertheless, this derived account of (some) novels as arguments has weaknesses. First, it seems basic to the concept of analogy that two different kinds of things are compared; "to say that two pigs are both fat is not to analogize" (Beardsley, p. 111). In light of this, it is at least questionable for many novels that would certainly appear to be arguments if there are any, whether they would count as arguments on the analogy analysis. Consider The Adventures of Huckleberry Finn. It is dubious that the events and the kind of racism described in the novel (first case) are different enough from the kind of racism the reader would be aware of (second case) to count as an analogy. Fisher and Filloy appear to be raising this question where we earlier saw them say of "aesthetic proofs" that "such proofs offer a special representation of reality somewhere between analogy and example." 
Second, the relativistic question must be asked: Which readers - those of Twain's time or our own? Insofar as the reader fills in at least the second case, the account has the seemingly absurd consequence, for example, that a dead author might never have had access to his or her own argument, as where George Orwell's 1984 is applied to today's Islamic regime in Iran. Surely, if 1984 is an argument, it is a general argument against modern totalitarianism (to the effect that it violates human nature); its being an argument doesn't depend on the reader filling in any particular second case, or for that matter, any moral. Similarly, if The Crucible is an argument, it is a general argument. In fact, Miller himself in the essay "Clinton in Salem" in the collection Echoes Down the Corridor analyzes the Bill Clinton/Monica Lewinsky hysteria in terms of those of the Salem witch trials.

These weaknesses are removed if the second case is lopped off the structure. What remains is the abduction of the principle from the first case, which itself is still an argument. There is an important kernel of truth in this atrophied model, though I do not think that it is yet adequate for fictional literature in general. (This is not meant to deny that for fables and contexts where the focus is on the rhetorical relationship between the text and the reader, Hunt's full model may be reasonable, so far as it goes.)

\section{A proposed structure of narrative arguments: Transcendent}

I think a better model is that some novels are transcendental arguments. I start with the idea that believability is "the master criterion of the novel" (as one reviewer of an ancestor of this paper put it), or at least is a central criterion of assessment. It is always reasonable to ask about a novel-is it successful "makebelieve"? No doubt the distinctive power and sweep of the novel is its unrivaled potentiality for intricate plot and associated character development. But for any believable plot/character development complex, we can ask-what principles or generalizations would have to be true about the real world (of human psychology, action, and society) in order for the fictional complex to be believable? Because this also always seems a reasonable question to ask, and because it can be an unanalyzed datum or given that a novel is indeed believable, the following transcendental argument scheme is generated: 
(1) This story (complex) is believable.

(2) This story is believable only if such and such principles operate in the real world.

(3) Therefore, such and such principles operate in the real world.

The believability premise, (1), is a proposition about the novel; it is not a self-referential claim made by the novel (although in degenerate cases such as parts of Henry Fielding's Tom Jones the novel seems to be explicitly claiming about itself that it is believable). If (1) were an implicit or explicit claim made by the novel, the question of whether this claim itself is believable would arise, and so on into an unpleasant regress. The idea is that in virtue of being believable (not claiming to be believable), a novel makes an argument telling us something about the real world. (2) expresses the specific inference license or rule that allows a novel to be an argument, according to the present theory; it is not something that any novelist need intend or even be aware of. (3) is the conclusion. It indicates which principles operate in the real world, which is primarily of human nature given the subject matter of novels. For illustration, consider Nussbaum (1990, pp. 139-140) on Henry James's The Golden Bowl:

The claim that our loves and commitments are so related that infidelity and failure of response are more or less inevitable features even of the best examples of loving is a claim for which a philosophical text would have a hard time mounting direct argument. It is only when, as here, we study the loves and attentions of a finely responsive mind such as Maggie's, through all the contingent complexities of a tangled human life, that...we have something like a persuasive argument that these features hold of human life in general.

As applied here, the conclusion (3) is the generalized (and rosy) "claim that our loves and commitments are so related that infidelity and failure of response are more or less inevitable features even of the best examples of loving," which is implicated by the believability of the plot/character development complex: "the loves and attentions of a finely responsive mind such as Maggie's, through all the contingent complexities of a tangled human life." 
The Nussbaum quotation also illustrates what is not all that uncommon: a vague, undeveloped recognition of the (transcendental) structure of the argument of a novel. Here is another example: Rodden (p. 155) says "in more didactic novels such as George Orwell's 1984, we are often aware of a presence arranging and evaluating ideas and characters in building a convincing argument." I am trying to shed some light on how characters can be "arranged" into an argument, not, trivially, how (e.g.) the speeches of characters sometimes overtly state arguments.

These considerations mean that (1)-(3) constitute a schematic meta-level representation of the argument of a believable novel, which, at the object level, is only indirectly expressed by the novel.

In what does believability consist? A novel's believability seems to be determined mostly by what can be called the 'internal' and "external" coherence of the event complex. I take Schultz (p. 233) to be succinctly explicating internal coherence where he says: "the events must be motivated in terms of one another...either one event is a causal (or otherwise probable) consequence of another; or some event's happening provides a character with a reason or motive for making another event happen" (cf., e.g., Cebik, p. 16). A novel is not believable if in it things keep happening for no apparent reason or in a way that is inadequately connected with the other events in the novel. Certainly, this applies to some degree to James Joyce's Ulysses and William Burroughs' Naked Lunch, for example.

But even if the events of a novel are fully connected, the novel may still not be believable because those connections do not cohere well with our widely shared basic intuitions about how human psychology and society not only actually, but necessarily work. This is the main component of external coherence. The believability of a novel requires that its plot and characters be developed in ways that generally conform to our fundamental shared intuitions about human nature. It might be wondered whether there is circularity here. I am saying both that the believability of a novel requires this kind of external coherence and, with the rule of inference (2) above, that the believability of a novel implicates certain truths of human nature. However, it seems there is no pernicious circularity, mainly because both of these statements are meta-level generalities. Even though at the object level a given novel's specific argument is only indirectly made by the novel itself, the reader or reviewer can summarize how the argument proceeds. And in this summary, there is no appearance of circularity. The summary starts with the unadorned premise that the novel-let Henry James's The Golden Bowl again be the example-is believable. It seems that general- 
ly, believability is experienced by the reader as a simple, unanalyzed datum or measure of the novel, continuously updated as the reader progresses through the novel and imaginatively engages with it. And, as Aristotle said about judging the happiness of a person, you do not know for sure about believability until you reach the novel's end. Of course, a few paragraphs back, there is already a conveniently short abbreviation of the remainder of this novel's argument. Put another way, the experience of a novel's believability is one thing, determining which specific truths of human nature are implicated may be quite another and may lie in the province of literary criticism using a method such as Fisher and Filloy's for extracting a novel's argument (discussed above in section 3 ). Believability might prompt the reader to reflect on what truths about human nature are implicated. But there is no necessity in this. The novel's argument is there, whether or not anybody notices.

A novel does not have to be realistic in order to be believable. The events of a novel can be far-fetched or remote, as in a science fiction, fantasy, or allegorical novel. Extremism of this sort seems to have little effect on believability so long as the events related are reasonably well-connected, and our fundamental shared assumptions about human nature, and about physical nature of course, are generally respected. Even with substantial alterations in fiction of physical or psychic reality, if the author's development of these alterations is internally consistent and coherent and exhibits firm 'suspension of the author's disbelief" (adapting Coleridge's phrase from 1817, p. 314), and if the author successfully depicts the characters as believing what is going on as if it is normal, this can make the novel believable for the reader. (The author in effect says, "suppose for the sake of argument...") On the other hand, a novelist may push the envelope regarding physical nature (a possible example is $\mathrm{H}$. P. Lovecraft's novella The Call of Cthulhu) or psychic reality (a possible example is Max Beerbohm's Zukeila Dobson), to the point where neither we, nor the characters, nor the author really understand what is going on. Here, believability breaks down, and consequently, no argument can get off the ground.

Allowing that novels can be arguments does not open the floodgates in a descent toward a view on the order of Lunsford, Ruszkiewicz, and Walters' in Everything's an Argument. Most relevantly, we may still hold that works of nonlinguistic art forms, such as pure music and painting, cannot be arguments. They are neither believable nor unbelievable - the category does not apply-because they are nonpropositional, though (e.g.) a painting might be realistic. Again, believability and realism are 
distinct notions. Similarly, no physical activity could be an argument. For example, suppose I want to convince you, who are skeptical, that bicycle touring is fun. You agree to try it out and come on a long-distance bike ride with me, after which you agree that it is fun. It might seem that the very physical activity of the bike ride constitutes an argument, since your experience of it convinces you that I am right (Groarke raises this question, p. 2). But surely, any argument here is present in virtue of certain propositions that are in play, expressible as (e.g.) 'the representative bicycle tour I experienced was fun, so bicycle touring is fun' (not necessarily a good argument). Physical activity itself is completely dumb with respect to argument and believability. Propositions must be in play before the question of believability can even be considered, because propositions are the objects of belief (what is believed), including "make-belief".

No argument is one thing, an uninteresting argument or a basic argument stock is another. Consider pulp fiction, "bodicerippers", and the like. These typically have formulaic plot and character development. They tell us little that we do not already know; their derivable conclusions about which principles or generalizations operate in the real world of human psychology, action, and society contain little insight. Still, they might be entertaining.

In using Coleridge's notion of suspension of disbelief, I do not mean to suggest that the believability of a novel involves believing that its event complex is true; rather, it involves believing that the event complex could have been true in a strong sense of 'could' - much stronger, for example, than that of mere logical possibility. As Aristotle famously said, "the poet's job is not to tell what has happened but the kind of things that can happen, i.e., the kind of events that are possible according to probability or necessity" (Poetics, 1451a 36-39). So while nonfictional narration (history, biography, etc.) aims at veracity, the novel aims at verisimilitude or depicting events and characters "according to probability or necessity," which I would explain as determined principally by internal and external coherence. This approach suggests a solution to the much-discussed "paradox of fiction/of fictional emotions" (i.e., how can it be that we have what appear to be genuine emotional responses to what we know is a fictional narrative?), a solution that I think uniquely gives believability a prominent role (I develop this solution in Plumer, forthcoming). Adapting a favorite example, we may be horrified by the events depicted in a horror film because they are believable; yet because we don't believe them, we don't flee the theater. So, being believable does not mean that something is on its way to being believed, for that path is never taken for some- 
thing you know to be fiction. With respect to fictional stories, internal and external coherence constitute more or less all there is to believability; with respect to nonfictional stories, belief may be the only thing there is to believability (possibility is logically implied by actuality). Hence, it is problematic to analyze 'believability' ('credibility,' 'plausibility') indifferently as it pertains to these two story domains, as do Fisher (1987) and Olmos (2013; forthcoming), and it would take quite a lot of work (and us, too far afield) to sort out similarities and differences.

No doubt in certain cases I may find a novel believable, whereas you do not. But I think that there is no fundamental relativity of believability because there is such a thing as human nature, which we all share and to which we have significant introspective or "privileged" access, or at least psychological attunement. ${ }^{1}$ The believable novel taps into and relies on these facts, bringing operant principles to the fore-which allows it to function as a perfectly effective psychological "trigger" (cf. Gaiman, p. xiii). If this general idea were not true, then it would be pretty inexplicable that there is widespread agreement about which novels are good novels. Being believable is a central necessary condition for a novel to be a good novel. So in the argument of a novel, the transcendental leap from "inner" to "outer" worlds is limited and facilitated. The leap is from our psychological experience of believability of the novel to the real world of human psychology, action, and society - which is the primary subject matter of all novels. This subject matter is basically human nature, I take it. The inner and outer worlds of the argument are significantly the same; it is not as if the worlds are distinct as, for example, thought and a brain in a vat, as in Putnam's memorable transcendental argument (Ch. 1). And, as Nagel (Ch. 12) forcefully argued, because after all we are human, we know what it is like to be human in a way we do not know what it is like to have a different nature, such as a bat's (and perceive the world primarily through echolocation, be capable of flying, etc.). Such philosophical considerations indicate that the principles evoked in the argument of the novel resonate in believabil-

\footnotetext{
${ }^{1}$ A recent influential article on introspection (Schwitzgebel) poses little threat to my points here concerning human nature and its operant principles, because the focus of the article is on the untrustworthiness of introspection of immediate conscious experience.

Differences among readers in the perceived believability of a novel may be largely attributable to relatively extraneous factors, such as the setting of the novel. For example, if I could get past the fantastic details of Tolkien's trilogy, I think I could better appreciate these novels as implicating truths of human nature.
} 
ity largely because they are true of human nature (I further develop this position, including addressing putative empirical counterexamples, in Plumer, forthcoming).

If this is correct, then the transcendental argument of the novel, (1)-(3) above, is not only valid (as a case of modus ponens) but is in a certain way probabilistically sound. At the object level of any novel, given that premise (1) is true and that our fundamental shared intuitions about human nature are generally true, the conclusion (3) is unlikely to be mistaken. However, at the interpretive meta-level, perhaps especially where the literary critic attempts to directly state which specific truths of human nature are implicated (i.e., flesh out premise (2)), no doubt errors may be committed. Nevertheless, this interpretive enterprise is worth pursuing, for it articulates, insofar as it is successful, the novel's contribution to human knowledge. Through the work of progressing through the believable novel and perceiving what survives or dominates in the various situations and conflicts (à la Fisher and Filloy), intuitions held by the reader about human nature become justified true beliefs, i.e., knowledge (if they are not already justified for the reader otherwise).

How, at the object level, does the novel move from premise (1) to the conclusion, (3)? The most interesting cases, and the height of the art form, are big, good, minimally didactic novels. I take the whole novel to be the argument. By inventing, in seemingly infinite detail, who the characters are and what happens to them, the novelist constructs a rich fictional world. The novelist probes, and shows us different ways we might be or live, shows us different ways we might interact, and shows us the consequences that might result from adopting these ways. Given that the novel is good, all this is believable, and so it unfolds largely according to recognizable principles and generalizations. But what gives the good novel a uniqueness of vision or greatness is where these implicated principles are tweaked, highlighted, unified, or pushed to limits with unexpected ramifications. Consider D. H. Lawrence's The Rainbow. Here is a passage about the novel's most reflective character (pp. 447-448):

"The stupid lights," Ursula said to herself, in her dark sensual arrogance. "The stupid, artificial, exaggerated town, fuming its lights. It does not exist really. It rests upon the unlimited darkness, like a gleam of coloured oil on dark water, but what is it?- nothing, just nothing."

In the tram, in the train, she felt the same. The lights, the civic uniform was a trick played, the people as they moved or sat were only dummies exposed. She could see, beneath their pale, wooden pretense of composure and 
civic purposefulness, the dark stream that contained them all.

In a line, Lawrence's view is that you should develop your passionate self to an equal or greater extent than your civic self; otherwise, your happiness will suffer.

Certainly, a novel's argument can be summarized or abbreviated, as above for The Golden Bowl and The Rainbow. But no such abbreviation is identical to the novel's argument. It is a very common view that being able to "accommodate incompatible moral responses" or interpretations is "typical of great literature" (Posner, p. 471; cf., e.g., Cebik, p. 22; Jones, p. 8; Fisher and Filloy above). I think this is confusion. Permit me to suggest that the view derives from our own limitations of finding it very difficult to take in, all at once as it were, the textured nuance of the argument of a work of great literature. So we focus on what we can handle ("any number of arguments become compatible with significant portions of the narrative"-Cebik, p. 22, my emphasis). A novel's argument is the one that "best fits", even if no reader has succeeded in adequately spelling it out, which does not mean that the reader will not be affected by the argument. A great novel's argument may operate on the mind like millions of years of evolution can operate on a creature, possibly radically transforming it. In the evolution case, it seems we find it essentially impossible to imagine the sequence of all the relevant events that could have transpired in such a large amount of time, so some form of creationism might tempt us. Similarly, reconstructing how a great novel's argument affects us may be nearly unfathomable, but that does not mean the effect is any less.

\section{Conclusion and summary}

If correct, my account means that the phenomenon of coming to see the world in a certain way as a result of reading a novel is misdiagnosed by the ethical critics we considered. The vehicle of persuasion includes argument after all; it is just that it may be very difficult to flesh out. The ability to get behind what ethical critics call "moral conversions" in some justificatory way is what I am affirming here.

I have tried to show that the argument of the novel functions as follows: (A) In encountering a novel, we already have a basic intuitive grasp of human nature and the principles that govern it. (B) The novel may evoke these principles in its story- 
telling (and may unify or extend them). (C) This makes the novel believable if it is otherwise coherent. (D) Through the work of progressing through the believable novel and perceiving what survives or dominates in the various situations and conflicts, intuitions held by readers about human nature become justified true beliefs or are transformed into special insights by literary greatness.

Acknowledgements: For comments on various earlier versions of the ideas presented here, I am grateful to Jason Dickenson, Robert Ennis, Trudy Govier, Louis Groarke, Lyra Hostetter, Paula Olmos, Kenneth Olson, Teresa Plumer, Lisa Tucker, and anonymous referees and audience members.

\section{References}

Ayers, L. (2010). Getting arguments out of narrative. Posted Oct. 19, 2010 on ARGTHRY, the listserv of the Ontario Society for the Study of Argumentation.

Beardsley, M.C. (1975). Thinking Straight. Principles of Reasoning for Readers and Writers ( $4^{\text {th }}$ edition). Englewood Cliffs, NJ: Prentice-Hall.

Booth, W.C. (1988). The Company We Keep. An Ethics of Fiction. Berkeley: University of California Press.

Booth, W.C. (1998). Why banning ethical criticism is a serious mistake. Philosophy and Literature 22, 366-393.

Cebik, L.B. (1971). Narratives and arguments. CLIO 1, 7-25.

Coleridge, S.T. (1817). Biographia Literaria Ch. 14. In: H.J. Jackson (Ed.), Samuel Taylor Coleridge (pp. 314-320), New York: Oxford University Press, 1985.

Crocker, T.P. (2002). An American novelist in the philosopher king's court. Philosophy and Literature 26, 57-74.

Doody, M. (2009). Philosophy of the novel. Revue Internationale de Philosophie 63, 153-163.

Fisher, W.R. and R.A. Filloy (1982). Argument in drama and literature: An exploration. In: J.R. Cox and C.A. Willard (Eds.), Advances in Argumentation Theory and Research (pp. 343-362, Ch. 15), Carbondale: Southern Illinois University Press.

Fisher, W.R. (1987). Human Communication as Narration. Toward a Philosophy of Reason, Value, and Action. Columbia: University of South Carolina Press.

Gaiman, N. (2015). Trigger Warnings. Short Fictions and Disturbances. New York: HarperCollins. 
Groarke, L. (2012). Commentary on "Cognition and Literary Ethical Criticism" by Gilbert Plumer. In: F. Zenker (Ed.), Argumentation: Cognition \& Community. Proceedings of the 9th International Conference of the Ontario Society for the Study of Argumentation (pp. 1-4), Windsor, ON (CD ROM).

Hariman, R. and J.L. Lucaites (2007). No Caption Needed. Iconic Photographs, Public Culture, and Liberal Democracy. Chicago: University of Chicago Press.

Hunt, L.H. (2009). Literature as fable, fable as argument. Philosophy and Literature 33, 369-385.

Jones, P. (1975). Philosophy and the Novel. Oxford: Oxford University Press.

Lamarque, P. (2014). The Opacity of Narrative. London: Rowman \& Littlefield.

Lawrence, D. H. (1915). The Rainbow. New York: The Viking Press.

Lunsford, A.A., J.J. Ruszkiewicz, and K. Walters (2012). Everything's an Argument ( $6^{\text {th }}$ edition). Boston: Bedford/St. Martin's.

Miller, A. (2000). Echoes Down the Corridor, S.R. Centola (Ed.). New York: Viking.

Nagel, T. (1979). Mortal Questions. Cambridge: Cambridge University Press.

Nussbaum, M.C. (1990). Love's Knowledge. Essays on Philosophy and Literature. Oxford: Oxford University Press.

Nussbaum, M.C. (1995). Poetic Justice. The Literary Imagination and Public Life. Boston: Beacon Press.

Olmos, P. (2013). Narration as argument. In: D. Mohammed and M. Lewinski (Eds.), Virtues of Argumentation. Proceedings of the 10th International Conference of the Ontario Society for the Study of Argumentation (pp. 1-14). Windsor, ON (CD ROM).

Olmos, P. (forthcoming). Story credibility in narrative arguments. In: Proceedings of the Eighth International Conference of the International Society for the Study of Argumentation.

Pappas, N. (1997). Fancy justice: Martha Nussbaum on the political value of the novel. Pacific Philosophical Quarterly 78, 278-296.

Plumer, G. (forthcoming). A defense of taking some novels as arguments. In: Proceedings of the Eighth International Conference of the International Society for the Study of Argumentation.

Posner, R.A. (2009). Law and Literature ( $3^{\text {rd }}$ edition). Cambridge: Harvard University Press. 
Putnam, H. (1981). Reason, Truth and History. Cambridge: Cambridge University Press.

Rodden, J. (2008). How do stories convince us? Notes towards a rhetoric of narrative. College Literature 35, 148-173.

Schultz, R.A. (1979). Analogues of argument in fictional narrative. Poetics 8, 231-244.

Schwitzgebel, E. (2008). The unreliability of naive introspection. Philosophical Review 117, 245-273.

Simard Smith, P.L. and A. Moldovan (2011). Arguments as abstract objects. Informal Logic 31, 230-261.

Tarbell, I. (1907). He knew Lincoln. In: The Stories of Ida Tarbell. New York: McClure, Phillips \& Co.

Walton, D. (2012). Story similarity in arguments from analogy. Informal Logic 32, 190-221. 